\title{
Contrasting effects of treatment with $\omega-3$ and $\omega-6$ essential fatty acids on peripheral nerve function and capillarization in streptozotocin-diabetic ratsn
}

\author{
K.C.Dines, M.A.Cotter, N.E.Cameron \\ Department of Biomedical Sciences, University of Aberdeen, Scotland, UK
}

\begin{abstract}
Summary. Essential fatty acid metabolism is impaired by diabetes mellitus and this may be important in the aetiology of peripheral nerve dysfunction. The effects of $\gamma$-linolenic acid ( $\omega-6)$ and fish oil ( $\omega-3)$ alone, and in combination, on nerve function and capillarization were examined in 2month streptozotocin-diabetic rats. Diabetes resulted in approximately $15 \%$ and $23 \%$ decreases in saphenous sensory and sciatic motor nerve conduction velocities, respectively $(p<0.001)$. Motor and sensory conduction velocities were in the non-diabetic range after both preventive and reversal $\omega-6$ treatment of diabetic rats $(p<0.001)$. No significant changes occurred in $\omega-6$ treated non-diabetic rats. Preventive $\omega$-3 treatment was largely ineffective. Reversal treatment with a combination of $\omega-6$ and $\omega-3$ fatty acids was marginally effective and improved motor $(p<0.05)$, but not sensory conduction velocity. In vitro measurement of sciatic nerve resistance to hypoxic conduction failure in diabetic rats revealed a $56 \%$ increase in the time taken for the com-
\end{abstract}

pound action potential amplitude to be reduced by $80 \%$ $(p<0.01)$ compared to non-diabetic rats. This was partially prevented by $\omega-6$ treatment $(29 \%$ increase, $p<0.01)$. Reversal $\omega-6$ treatment had a lesser effect ( $37 \%$ increase, $p<0.05$ compared to untreated diabetic rats). $\omega-3$ treatment had no significant effect on conduction failure time. Sciatic endoneurial capillary density increased by $11 \%$ with preventive $\omega-6$ treatment $(p<0.05)$, but was unaffected by reversal $\omega-6$ and by $\omega-3$ treatments. These results demonstrate the specificity of $\omega$-6 essential fatty acids in improving diabetic nerve function and highlight an antagonism exerted by $\omega-3$ components, which may have therapeutic implications.

Key words: Streptozotocin diabetes, neuropathy, nerve conduction, essential fatty acids, fish oil, $\gamma$-linolenic acid, ischaemia, angiogenesis.
Early changes in nerve function are characterised by reduced nerve conduction velocity ( $\mathrm{NCV}$ ) and an increase in resistance to hypoxic conduction failure (RHCF) in animal models and patients with diabetes mellitus [1]. The vascular hypothesis provides an explanation of the aetiology of these changes, based upon observations of decreased nerve blood flow and consequent endoneurial hypoxia in experimental diabetes [2-4]. Reduced blood flow has also been directly and indirectly demonstrated in diabetic patients with neuropathy [5,6] and endoneurial hypoxia is present [7]. In non-diabetic rats and patients, chronic hypoxia is associated with the development of reduced NCV and increased RHCF [8-11]. Thus, endoneurial hypoxia, irrespective of cause, can impose a stress sufficient to alter nerve function and lead to increased dependence on anaerobic metabolism $[8,12]$. Several studies involving vasodilators have shown improvements in nerve function related to endoneurial perfusion in diabetic rats [3,13-17]. Thus, a strong argument may be made for cause and effect between reduced nerve blood flow and nerve conduction deficits $[1,3]$.

Diabetes results in an inhibition of $\Delta$-6-desaturase, the enzyme that converts the $\omega-6$ essential fatty acid, linoleic acid, to $\gamma$-linolenic acid (GLA). This leads to an approximately $25 \%$ decrease in the synthesis of prostanoid/eicosanoid precursors such as arachidonic acid [18]. In addition, Ward et al. [19] found that production of 6-keto prostaglandin $(\mathrm{PG}) \mathrm{F}_{1 \alpha}$, the stable metabolite of prostacyclin, was reduced by $46 \%$ in sciatic nerve from chronic diabetic rats. Although linoleic acid treatment alone does not affect diabetic neuropathy [20,21], several studies have shown that nerve dysfunction in diabetic rats may be prevented by evening primrose (Oenothera biennis) oil (EPO) treatment [21-23]. EPO has a complex composition and contains approximately $9 \%$ GLA. While it is thought that GLA may be the active component in EPO, an effect of GLA has not been directly demonstrated. The primary aim of this investigation, therefore, was to assess 
Table 1. Body weights and plasma glucose levels for all groups of rats.

\begin{tabular}{|c|c|c|c|c|}
\hline Group & $n$ & $\begin{array}{l}\text { Start weight } \\
(\mathrm{g})\end{array}$ & $\begin{array}{l}\text { Final weight } \\
\text { (g) }\end{array}$ & $\begin{array}{l}\text { Plasma glucose } \\
(\mathrm{mmol} / 1)\end{array}$ \\
\hline \multicolumn{5}{|l|}{ Non-diabetic } \\
\hline Control & 12 & $449 \pm 12$ & - & $8.9 \pm 0.2$ \\
\hline GLA-treated & 11 & $507 \pm 11$ & $560 \pm 16$ & $9.0 \pm 0.2$ \\
\hline \multicolumn{5}{|l|}{ Diabetic } \\
\hline 1 month & 11 & $468 \pm 9$ & $414 \pm 11$ & $35.9 \pm 2.2$ \\
\hline GLA-treated reversal & 11 & $467 \pm 12$ & $379 \pm 9$ & $40.8 \pm 1.8$ \\
\hline Fish oil-treated preventive & 10 & $443 \pm 7$ & $371 \pm 8$ & $37.1 \pm 1.2$ \\
\hline GLA + fish oil-treated reversal & 11 & $460 \pm 8$ & $341 \pm 10$ & $46.5 \pm 1.9$ \\
\hline
\end{tabular}

Data are group means \pm SEM. GLA, $\gamma$-linolenic acid

the effects of pure GLA on nerve function and vascular supply in preventive and reversal studies.

In recent years there has been great interest in the effect of $\omega$-3 essential fatty acids, found particularly in fish oil, on prevention of atherosclerosis and hypertension in animal models and patients with vascular disease [24]. $\omega-3$ fatty acids can act as precursors for the production of vasoactive prostanoids [24], stimulate synthesis of unidentified relaxing factors from cultured endothelial cells [25], and improve endothelium-dependent relaxation in aorta from hypertensive rats [26]. As fish oil treatment has recently been reported to improve vascular function in diabetic patients [27], a second aim of the investigation was to determine the effects of fish oil on diabetic nerve function. In addition, a combination of GLA and fish oil was administered to a group of diabetic rats to evaluate the interaction between $\omega-3$ and $\omega-6$ metabolic pathways.

\section{Materials and methods}

Mature male 19-week-old Sprague-Dawley rats (Aberdeen University colony) were used. Non-diabetic rats were employed as an onset control group. Other groups of rats were made diabetic by injection of streptozotocin $(40 \mathrm{mg} / \mathrm{kg}$ in $20 \mathrm{mmol} / \mathrm{l}$ sodium citrate buffer, $\mathrm{pH} 4.5$, i.p.). Diabetes was verified $24 \mathrm{~h}$ later by estimation of hyperglycaemia and glycosuria (Visidex II and Diastix; Ames, Slough, Bucks., UK). On the day of final experiments, samples of blood from the tail vein were taken for later determination of plasma glucose using a standard test kit (GOD-Perid method; Boehringer Mannheim, Mannheim, Germany).

One and two-month untreated diabetic control groups were employed in addition to a non-diabetic group treated with GLA for 2 months. The total duration of diabetes in treated groups was 2 months with treatment being either preventive or reversal. Preventive experiments involved treating the animal from the induction of diabetes whereas reversal treatment involved commencing treatment after 1 month of untreated diabetes. All groups treated with GLA (Scotia Pharmaceuticals, Guildford, Surrey, UK) received $260 \mathrm{mg} /$ day via gavage as this dose is similar to that contained in the $10 \%$ dietary supplement of EPO used in a previous study [11]. The group treated with fish oil (Scotia) received approximately $840 \mathrm{mg} /$ day of the active components (docosahexaenoic and eicosapentaenoic acid) as a $10 \%$ dietary supplementation. A further reversal group of diabetic rats were fed a combination of GLA and fish oil by dietary admixture in such a ratio that the amount of the putative active components was equal for the two constituents, i. e. $260 \mathrm{mg} /$ day $\omega-6$ and $260 \mathrm{mg} /$ day $\omega-3$ essential fatty acids $(3.3 \%$ dietary supplementation).
In final experiments (1-1.5 g/kg urethane anaesthesia, i.p.), nerve conduction velocity was measured in vivo between the sciatic notch and the knee for the sciatic motor branches supplying the tibialis anterior (peroneal division) and the gastrocnemius (tibial division) muscles. Conduction velocity was also measured in the sensory saphenous nerve between the groin and the ankle. Nerve temperature was maintained at $37.0-37.5^{\circ} \mathrm{C}$ by radiant heat. Methods have previously been described in detail [28, 29].

Sciatic nerve resistance to hypoxia was measured in vitro as previously described [21]. The contralateral sciatic trunk was removed and mounted on bipolar stimulating (proximal end) and recording (distal end) electrodes in a chamber containing Krebs solution at $35^{\circ} \mathrm{C}$. Glucose concentration in the bath was $5.5 \mathrm{mmol} / \mathrm{l}$ for nerves from non-diabetic rats and $40 \mathrm{mmol} / \mathrm{l}$ for diabetic rats. Nerves were equilibrated in Krebs solution bubbled with $95 \% \mathrm{O}_{2}, 5 \% \mathrm{CO}_{2}$ for $30 \mathrm{~min}$ before filling the chamber with mineral oil pre-gassed for $1 \mathrm{~h}$ with $100 \% \mathrm{~N}_{2}$. Nerve stimulation was just supramaximal (pulses being $1 \mathrm{~Hz}, 0.05 \mathrm{~ms}$ wide, $10 \mathrm{~mA}$ ) and compound action potential amplitude was measured at 2 -min intervals until it fell below $10 \%$ of the initial value.

Just before killing the rats, approximately $2.5 \mathrm{~cm}$ of the sciatic nerve trunk was removed along with muscles to act as a support tissue. Samples were frozen in iso-pentane pre-chilled in liquid nitrogen. $10 \mu \mathrm{m}$ cryostat sections were stained for alkaline phosphatase to demonstrate the capillaries [30]. Three sections were taken, each $90 \mu \mathrm{m}$ apart, and capillaries in the nerve fascicles were counted with the aid of a projection microscope. Outlines of the fascicles were traced and their area measured using a computer-linked digitising pad. From this, average capillary density was obtained for repeated sampling between the sciatic notch and the knee.

\section{Statistical analysis}

Data are expressed as group means \pm SEM. A one-way ANOVA was carried out, followed by Bonferroni $t$-tests corrected for multiple comparisons, to assign significance levels to individual between-group comparisons when overall significance was attained $(p<0.05)$.

\section{Results}

Data for body weights before and after treatment and plasma glucose concentrations are shown in Table 1 . All diabetic groups displayed a large rise in plasma glucose levels and approximately $25 \%$ reductions in body weight $(p<0.001)$ which were unaffected by treatment.

Data for sciatic motor NCV are presented in Figure $1 \mathrm{~A}$ as the average value for conduction velocity in 

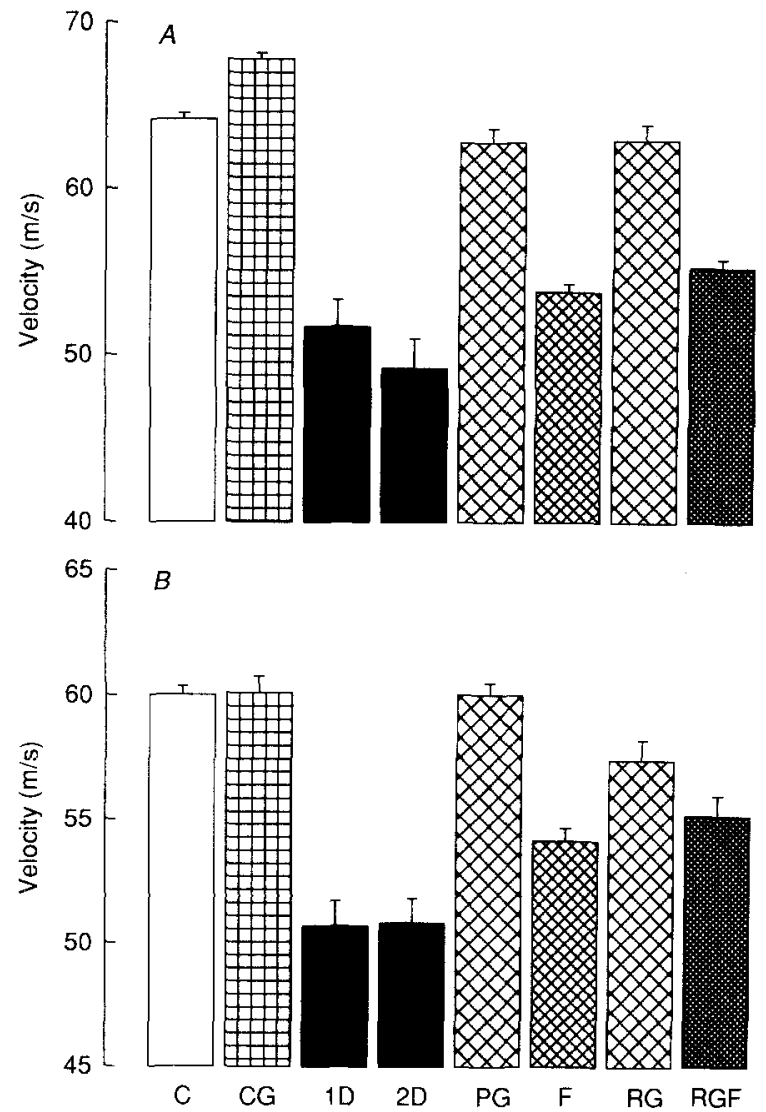

Fig. 1A, B. Sciatic motor (A) and saphenous sensory (B) conduction velocity in non-diabetic and diabetic groups with and without essential fatty acid treatment. C, non-diabetic control group $(n=12)$; $C G$, non-diabetic control group treated with $\gamma$-linolenic acid for 2 months $(n=11) ; 1 \mathrm{D}, 1$-month diabetic group $(n=11) ; 2 \mathrm{D}$, 2 -month diabetic group ( $n=20)$; $\mathrm{PG}$, diabetic group given preventive $\gamma$-linolenic acid treatment for 2 months $(n=25) ; \mathrm{F}$, diabetic group given preventive fish oil treatment for 2 months $(n=10)$; RG diabetic group untreated for 1 month and then given reversal $\gamma$-linolenic acid treatment for 1 month $(n=11)$; RGF diabetic group untreated for 1 month and then given reversal treatment with a mixture of fish oil and $\gamma$-linolenic acid $(n=11)$. Error bars are SEM

branches innervating gastrocnemius and tibialis anterior muscles. After 1 month of untreated diabetes, motor NCV was decreased by approximately $25 \%$ and showed no further significant decline after 2 months $(p<0.001)$. Motor NCV was maintained within the non-diabetic range by preventive treatment and was returned to the non-diabetic range by reversal treatment with GLA $(p<0.01)$. Preventive treatment of non-diabetic animals with GLA was without effect. Treatment of diabetic rats with fish oil caused a $31 \%$ prevention of the motor NCV deficit that was not statistically significant. For the reversal group treated with a mixture of GLA and fish oil, there was a marginal improvement in motor NCV $(p<0.05)$, which was significantly less $(p<0.05)$ than for reversal GLA treatment alone.

Figure $1 \mathrm{~B}$ shows sensory saphenous $\mathrm{NCV}$, which was approximately $15 \%$ reduced by untreated diabetes $(p<0.001)$. Sensory NCV was within the non-diabetic range for both preventive and reversal GLA treatment, while non-diabetic rats that received GLA treatment did

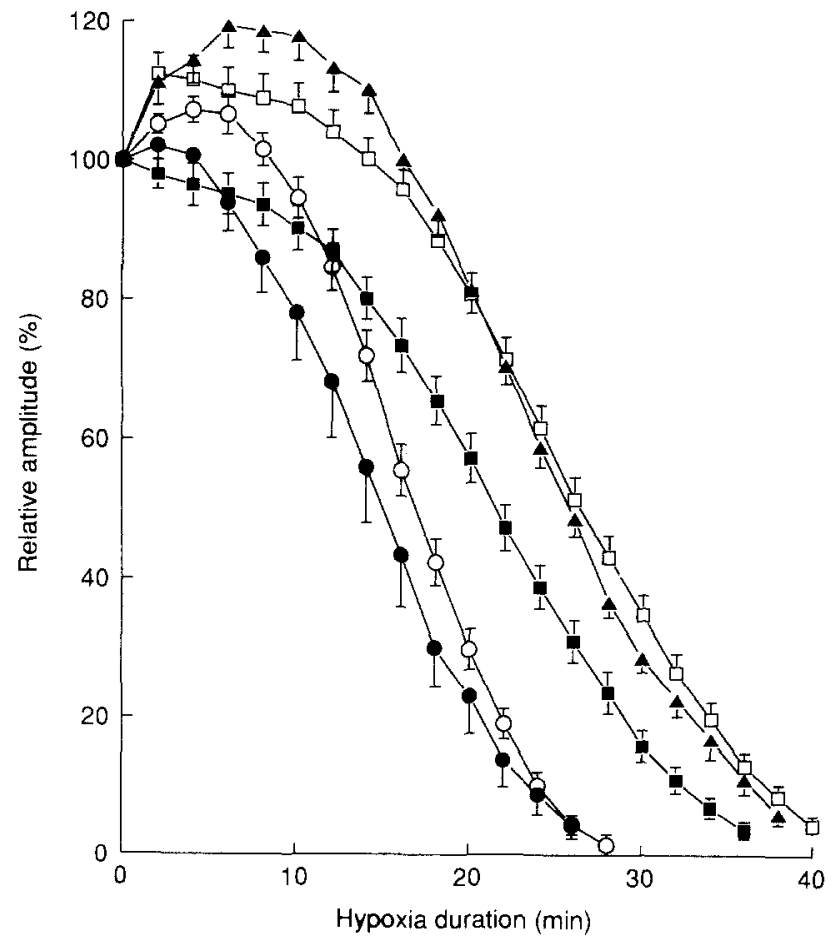

Fig. 2. Sciatic nerve resistance to hypoxic conduction failure in vitro for non-diabetic control (O), $n=12 ; \gamma$-linolenic acid treated control (๑), $n=11 ; 2$-month diabetic $(\square), n=20$; preventive $\gamma$-linolenic acid treated diabetic $(\square), n=25$; and preventive fish oil treated diabetic (A), $n=10$, groups. Error bars are SEM

not show any significant differences compared to untreated control rats. Treatment of diabetic rats with fish oil produced a $33 \%$ prevention of the sensory NCV deficit that was not statistically significant. Reversal treatment of diabetic rats with a mixture of GLA and fish oil produced a modest improvement in NCV $(p<0.05)$ compared to the untreated diabetic group.

Sciatic nerve RHCF curves for selected groups are shown in Figure 2. Non-diabetic control and 2-month untreated diabetic groups displayed similar hyper-excitability [31] over the first $8 \mathrm{~min}$ of hypoxia. Following this, there was a rapid decline in compound action potential amplitude in the nerves from non-diabetic rats and a greatly prolonged decline for nerves from the untreated diabetic group. Preventive GLA treatment blunted the initial phase of hyper-excitability in both diabetic and non-diabetic groups (6-8 min, $p<0.05$ comparing treated and untreated non-diabetic rats; $2-14 \mathrm{~min} p<0.01 \mathrm{com}$ paring treated and untreated diabetic rats). Fish oil treatment resulted in a tendency towards supra-normal hyperexcitability $(0.1>p \geq 0.05,6-14$ min compared to the untreated diabetic group), followed by a rate of decline similar to that of the 2-month untreated diabetic group. Preventive GLA treatment reduced the alterations in the RHCF profile, although full prevention of the diabetes-induced changes was not observed.

The durations of hypoxia necessary for the compound action potential amplitude to fall by $50 \%\left(\mathrm{~T}_{50}\right)$ and $80 \%$ $\left(T_{80}\right)$ are shown in Figure 3. These parameters progressively increase with 1 and 2 months of untreated diabetes, the 2 -month values being significantly elevated compared 

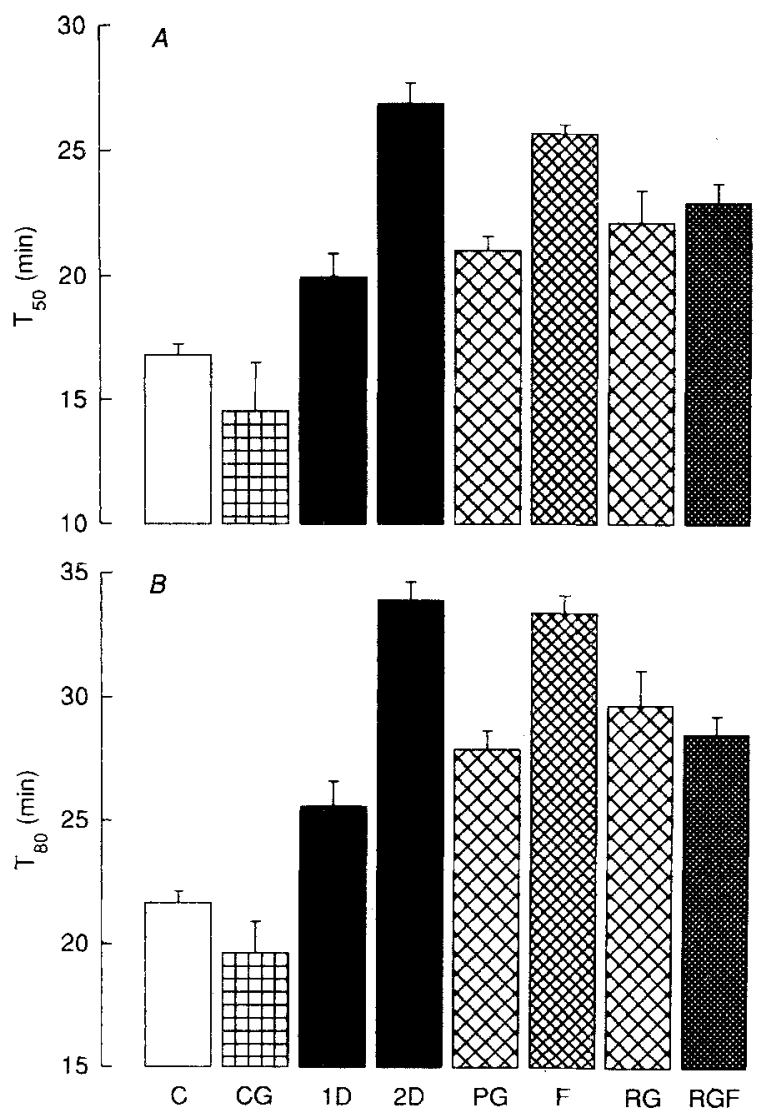

Fig. 3A, B. Durations of hypoxia necessary for $50 \%\left(T_{50}\right)(\mathbf{A})$ and $80 \%\left(\mathrm{~T}_{80}\right)$ (B) conduction failure in non-diabetic and diabetic groups with and without essential fatty acid treatment. $C$, nondiabetic control group $(n=12) ; \mathrm{CG}$, non-diabetic control group treated with $\gamma$-linolenic acid for 2 months $(n=11) ; 1 \mathrm{D}, 1$-month diabetic group ( $n=11) ; 2 \mathrm{D}, 2$-month diabetic group $(n=20)$; PG, diabetic group given preventive $\gamma$-linolenic acid treatment for 2 months $(n=25) ; \mathrm{F}$, diabetic group given preventive fish oil treatment for 2 months $(n=10)$; RG diabetic group untreated for 1 month and then given reversal $\gamma$-linolenic acid treatment for 1 month ( $n=11)$; RGF diabetic group untreated for 1 month and then given reversal treatment with a mixture of fish oil and $\gamma$-linolenic acid $(n=11)$. Error bars are SEM

to the control group $(p<0.001)$. $\mathbf{T}_{50}$ values were significantly reduced by preventive $(p<0.001)$ and reversal treatment with GLA $(p<0.05)$ when compared to 2month untreated diabetic rats, however, there were no significant differences from the 1-month diabetic group. $\mathrm{T}_{80}$ results for GLA preventive and reversal treatments and for reversal treatment with the mixture of GLA and fish oil were also significantly less than for untreated diabetic rats $(p<0.001, p<0.05$ and $p<0.01$, respectively). Preventive treatment of diabetic rats with fish oil was ineffectual when compared to diabetic controls. $T_{50}$ and $T_{80}$ data from GLA-treated non-diabetic rats did not differ significantly from those for the untreated control group.

Sciatic endoneurial capillary densities are shown in Figure 4. Preventive GLA treatment of diabetic rats caused $11 \%$ and $13 \%$ increases in capillarization compared with non-diabetic $(p<0.05)$ and 2 -month diabetic groups $(p<0.001)$, respectively. There were no significant effects of diabetes or treatment for any of the other groups.

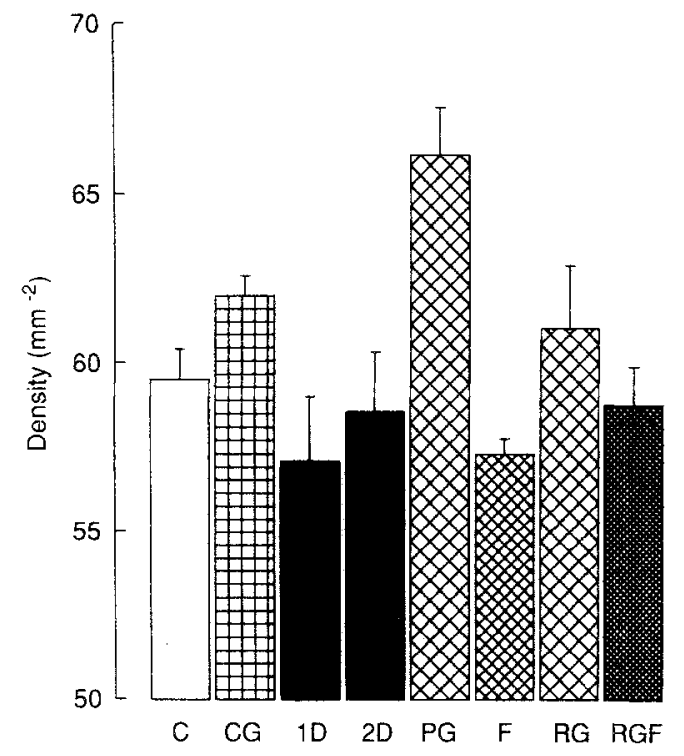

Fig. 4. Sciatic nerve endoneurial capillary density for non-diabetic and diabetic groups with and without essential fatty acid treatment. $\mathrm{C}$, non-diabetic control group $(n=12) ; \mathrm{CG}$, non-diabetic control group treated with $\gamma$-linolenic acid for 2 months $(n=11) ; 1 \mathrm{D}, 1$ month diabetic group $(n=11) ; 2 \mathrm{D}, 2$-month diabetic group $(n=20)$; PG, diabetic group given preventive $\gamma$-linolenic acid treatment for 2 months $(n=25) ; \mathrm{F}$, diabetic group given preventive fish oil treatment for 2 months $(n=10)$; RG diabetic group untreated for 1 month and then given reversal $\gamma$-linolenic acid treatment for 1 month $(n=11)$; RGF diabetic group untreated for 1 month and then given reversal treatment with a mixture of fish oil and $\gamma$-linolenic acid $(n=11)$. Error bars are SEM

\section{Discussion}

The data demonstrate that GLA is effective in preventing and reversing motor and sensory NCV deficits in diabetic rats, and that it reduces, but does not reverse, the development of RHCF. Thus, it is likely that GLA is the active constituent of EPO. The effects of $\omega-6$ fatty acids markedly contrast with those of the $\omega-3$ components found in fish oil, which proved considerably less effective in preventing neurological abnormalities. When mixed with fish oil, the beneficial effect of GLA was attenuated, suggesting antagonism between $\omega-3$ and $\omega-6$ metabolic pathways.

GLA is converted to dihomo-GLA and then to arachidonic acid, both of which act as substrates for the cyclooxygenase mediated synthesis of vasoactive prostanoids. Vasodilator $\mathrm{PGE}_{1}$ formation requires dihomo-GLA, whereas vasodilator prostacyclin and $\mathrm{PGE}_{2}$ and vasoconstrictor thromboxane $\mathrm{A}_{2}\left(\mathrm{Tx}_{2}\right)$ are produced from arachidonic acid [32]. In a previous investigation, the effect of EPO on NCV in diabetic rats was completely blocked by the cyclo-oxygenase inhibitor, flurbiprofen [33]. Analogues of $\mathrm{PGE}_{1}$, prostacyclin and $\mathrm{PGE}_{2}$ improve $\mathrm{NCV}$ in diabetic rats $[16,34,35]$. The $\omega-3$ component, eicosapentaenoic acid, is metabolised similarly to arachidonic acid, producing vasodilator and vasoconstrictor homologues that are generally less potent than their $\omega-6$ counterparts [24]. Given the observations on nerve function, this suggests that one putative beneficial effect of fish oil, substitution of a compound with low platelet aggregant and 
vasoconstrictor activity for $\mathrm{TxA}_{2}$ [24], is relatively unimportant in diabetic neuropathy. In addition $\omega-3$ and $\omega-6$ components are metabolised by the same or similar enzyme sequences, for which they compete. The $\omega$-3 essential fatty acids are more effective antagonists of $\omega-6$ metabolism than vice versa [36] and eicosapentaenoic acid also inhibits the conversion of dihomo-GLA to arachidonic acid [24]. For combined $\omega-3$ and $\omega-6$ treatment, this has the effect of enhancing $\mathrm{PGE}_{1}$ synthesis at the expense of reduced prostacyclin and $\mathrm{PGE}_{2}$ production [32]. As GLA-mediated increases in NCV were blunted by fish oil, it is likely that prostacyclin and/or $\mathrm{PGE}_{2}$ mediate the actions of GLA and EPO.

Fish oil treatment produces several beneficial effects, for example, increased anti-inflammatory activity [37] and reduced risk factors for coronary disease, including the prevention of coronary thrombosis and atherosclerosis [38]. Part of this action may depend upon augmentation of vascular endothelium-dependent relaxation $[25$, 26]. A recent study has also demonstrated a similar beneficial effect on the general circulation of diabetic patients [27]. Although fish oil treatment did not cause statistically significant effects, both motor and sensory NCV deficits were approximately $30 \%$ less than for untreated diabetes. This investigation used a large number of groups. To avoid type I errors arising from multiple comparisons the conservative Bonferroni post hoc statistical test was employed. However, this increases the possibility of type II errors. If a simpler experimental design had been considered, with only control, 2-month diabetic, and fish oiltreated diabetic groups, then using the less conservative Student-Newman-Keuls post hoc test, both sensory and motor NCV effects would have been significant $(p<0.05)$. Therefore, it is plausible that fish oil does have a real, albeit modest, beneficial effect on NCV. Vasa nervorum blood flow may be more strongly under the control of endothelial prostacyclin synthesis than for some other vascular beds. Thus, any advantage proffered by fish oil for prevention of resistance vessel atherosclerosis or preservation of endothelial integrity may be offset by inhibition of the already compromised prostacyclin synthesis, which depends upon a lack of substrate availability [19] consequent on impaired $\Delta 6$-desaturation of linoleic acid [32]. It is, therefore, important to consider whether potential adverse consequences of $\omega-3$ treatment on vasa nervorum $\omega-6$ metabolism are outweighed by the overall cardiovascular benefits in diabetic patients. Given that fish oil and EPO have similar anti-arterial disease and anti-hypertensive properties in animal models and non-diabetic patients $[39,40]$, it would be interesting to determine whether they have comparable general cardiovascular effects for diabetic patients.

While GLA treatment improved sciatic nerve RHCF, the preventive regimen was less successful than predicted by a previous study using EPO [21]. This may be due to the use of different treatment methods. Thus, this study employed once daily treatment by gavage, whereas for the EPO study dietary admixture ensured that treatment was available continuously. Therefore, rapidly metabolised components may not be as available over time with gavage compared to dietary supplementation. GLA is very rapidly metabolised [21] and the effects of EPO on NCV are short-lived, with a return to diabetic values within $24 \mathrm{~h}$ of the cessation of short-term treatment [41].

From the RHCF profiles it is notable that GLA blunted the initial hyper-excitability phase in nerves from diabetic and non-diabetic rats. This agrees with a previous study using EPO [21]. Conversely, fish oil-treated diabetic rats displayed supra-normal hyper-excitability. The mechanisms underlying hyper-excitability and RHCF are poorly understood but are accompanied by a degree of axonal depolarisation that reduces excitation thresholds [42] and may depend on changes in membrane-bound calcium levels that modulate axonal excitability [43]. The reasons why GLA and fish oil changed hyper-excitability in opposite directions are unclear, but these effects probably do not result from direct changes in membrane properties as both treatments would be expected to produce similar reductions in membrane fluidity $[44,45]$. Thus, these actions may depend on products of eicosanoid metabolism, which can acutely alter nerve function [46].

RHCF appears to arise because of changes in nerve metabolism towards greater utilisation of anaerobic glycolysis [12]. The main stimulus may be endoneurial hypoxia as RHCF is also found in non-diabetic rats reared under hypoxic conditions [8]. In vivo experiments suggest that there is also a contribution from increased substrate availability due to hyperglycaemia [47]. Exposure to an elevated glucose concentration in vitro also induces RHCF in nerves from non-diabetic rats [48], however, this takes several hours. Under the conditions employed in the present investigation, RHCF is relatively independent of the level of bath glucose [N. Cameron, M. Cotter, D. Cox, unpublished observations] and similar data has been obtained for endoneurial preparations from diabetic and non-diabetic rats [49]. Given that some vasodilator treatments $[13,14]$ markedly reduced the development of RHCF in diabetic rats it is, therefore, unlikely that chronic hyperglycaemia makes a major contribution. RHCF may be advantageous to nerve function in diabetic rats because of an increased ability to cope with episodes of inadequate perfusion, for example, during intense activity. RHCF remained elevated in both preventive and reversal groups, suggesting that not all facets of nerve metabolism or vascular dysfunction were corrected by GLA treatment at the dose employed.

It is not clear whether nerve dysfunction in diabetic rats could be completely rectified by any single treatment. Factors other than essential fatty acid dysmetabolism are likely to contribute to vascular dysfunction and the reduction in nerve blood flow [1-6]. Thus, there are alterations in vascular reactivity to catecholamines and angiotensin II, and an increase in the activity of voltage-dependent calcium channels $[13-15,17]$. Polyol pathway flux has deleterious effects on vessel contraction and relaxation $[50,51]$, as well as reducing tissue anti-oxidant protection mechanisms [52]. Increased oxygen-free radical activity in diabetes causes the formation of lipid hydroperoxides [53] which inhibit prostacyclin synthetase [54], reducing the prostacyclin/ $\mathrm{TxA}_{2}$ ratio in favour of vasoconstriction and platelet aggregation. Treatment with butylated hydroxytoluene, a scavenger of oxygen free radicals, prevented 
$\mathrm{NCV}$ abnormalities in diabetic rats [55]. In addition, treatment with aminoguanidine, which also prevents lipid peroxidation [56], inhibits the formation of advanced glycation end-products [57] and improves sciatic nerve blood flow [58], was effective in preventing NCV deficits. EPO also contains the anti-oxidant, vitamin E. However, the data for GLA treatment (no anti-oxidant) suggest that the main effect of EPO probably results from prostanoid production.

Angiogenesis was found in vasa nervorum of the preventive GLA-treated group, which agrees with the results of a previous study using EPO [21]. Vessel growth is a consequence of long-term increases in blood flow [59], and has been noted in nerves and skeletal muscles of diabetic rats following vasodilator treatment $[13,14,16$, 17]. The results for reversal GLA treatment, however, emphasise the point that angiogenesis is not a prerequisite for functional improvements. It seems that either the increase in blood flow necessary to ameliorate NCV deficits is less than that required to instigate capillary growth [15] or that the process of angiogenesis is lengthy and lags behind nerve conduction improvements. The latter is relatively rapid; using $\mathrm{EPO}$, the $\mathrm{NCV}$ deficit following 3 months of streptozotocin-diabetes was corrected within 4 days [41].

In conclusion, the data suggest that GLA is the main active component of EPO and highlight the importance of $\omega-6$ over $\omega-3$ components and the negative interaction between them. Abnormal essential fatty acid metabolism appears to be a primary factor in the aetiology of nerve dysfunction in experimental diabetes, the likely result being decreased nerve blood flow and endoneurial hypoxia. As for EPO [60], GLA treatment may have therapeutic value in patients and has the potential advantage of a reduced oil intake.

Acknowledgements. This work was supported in part by a grant from the British Diabetic Association. KCD was funded by a research studentship from Scotia Pharmaceuticals, who supplied the GLA and fish oil. We are grateful to Mr. S. McBain and the staff of the animal house for the excellent care of the rats and to Ms I. Fordyce for preparing the sections for capillary density determination.

\section{References}

1. Low PA, Tuck RR, Takeuchi M (1987) Nerve microenvironment in diabetic neuropathy. In: Dyck PJ, Thomas PK, Asbury AK, Winegrad AI, Porte D (eds) Diabetic neuropathy. Saunders, Philadelphia, pp 266-278

2. Tuck RR, Schmelzer JD, Low PA (1984) Endoneurial blood flow and oxygen tension in the sciatic nerves of rats with experimental diabetic neuropathy. Brain 107: 935-950

3. Cameron NE, Cotter MA, Low PA (1991) Nerve blood flow in early experimental diabetes in rats: relation to conduction deficits. Am J Physiol 261: E1-E8

4. Monafo WM, Eliasson S, Shimazaki S, Sugimoto H (1988) Regional blood flow in resting and stimulated sciatic nerve of diabetic rats. Exp Neurol 99: 607-614

5. Tesfaye S, Harris N, Jacubowski J, Mody C, Ward J (1990) Impaired blood tow and arterio-venous shunting in human diabetic sural nerve. Diabetic Med 7 [Suppl 2]: 29 A (Abstract)

6. Tesfaye S, Harris ND, Wilson RM, Ward JD (1992) Exercise-induced conduction velocity increment: a marker of peripheral nerve blood flow in diabetic neuropathy. Diabetologia 35: 155 159

7. Newrick PG, Wilson AJ, Jakubowski J, Boulton AJM, Ward JD (1986) Sural nerve oxygen tension in diabetes. BMJ 293: 10531054

8. Low PA, Schmelzer JD, Ward KK, Yao JK (1986) Experimental chronic hypoxic neuropathy: relevance to diabetic neuropathy. Am J Physiol 250: E94-E99

9. Masson EA, Church SE, Woodcock AA, Hanley SP, Boulton AJM (1988) Is resistance to ischaemic conduction failure induced by hypoxia? Diabetologia 31: 762-765

10. Malik RA, Masson EA, Sharma AK et al. (1990) Hypoxic neuropathy: relevance to human diabetic neuropathy. Diabetologia 33: $311-318$

11. Young MJ, Veves A, Walker MG, Boulton AJM (1992) Correlations between nerve function and tissue oxygenation in diabetic patients: further clues to the aetiology of diabetic neuropathy? Diabetologia 35: 1146-1150

12. Low PA, Ward K, Schmelzer JD, Brimijoin S (1985) Ischemic conduction failure and energy metabolism in experimental diabetic neuropathy. Am J Physiol 248: E457-E462

13. Cameron NE, Cotter MA, Ferguson K, Robertson S, Radcliffe MA (1991) Effects of chronic $\alpha$-adrenergic receptor blockade on peripheral nerve conduction, hypoxic resistance, polyols, $\mathrm{Na}^{+}$$\mathrm{K}^{+}$-ATPase activity, and vascular supply in STZ-D rats. Diabetes 40: $1652-1658$

14. Cameron NE, Cotter MA, Robertson S (1992) Angiotensin converting enzyme inhibition prevents development of muscle and nerve dysfunction and stimulates angiogenesis in streptozotocindiabetic rats. Diabetologia 35: 12-18

15. Robertson S, Cameron NE, Cotter MA (1992) The effect of the calcium antagonist nifedipine on peripheral nerve function in streptozotocin-diabetic rats. Diabetologia 35: 11131117

16. Cotter MA, Dines KC, Cameron NE (1993) Prevention and reversal of motor and sensory peripheral nerve conduction abnormalities in streptozotocin-diabetic rats by the prostacyclin analogue iloprost. Naunyn-Schmiedeberg's Arch Pharmacol 347: $534-540$

17. Maxfield EK, Cameron NE, Cotter MA (1992) Angiotensin II receptor blockade improves nerve function in streptozotocindiabetic rats. Diabetic Med 9 [Suppl2]: P59 (Abstract)

18. Horrobin DF (1990) $\gamma$ Linolenic acid. Rev Contemporary Pharmacotherapy 1: $1-41$

19. Ward KK, Low PA, Schmelzer JD, Zochodne DW (1989) Prostacyclin and noradrenaline in peripheral nerve of chronic experimental diabetes in rats. Brain 112: 197-208

20. Houtsmuller AJ, van Hal-Ferwerda J, Zahn KJ, Henkes HE (1982) Favourable influences of linoleic acid on the progression of diabetic micro- and macroangiopathy in adult onset diabetes mellitus. Prog Lipid Res 20: 377-386

21. Cameron NE, Cotter MA, Robertson S (1991) Effects of essential fatty acid dietary supplementation on peripheral nerve and skeletal muscle function and capillarisation in streptozotocin diabetic rats. Diabetes $40: 532-539$

22. Julu POO (1988) Essential fatty acids prevent slowed nerve conduction velocity in streptozotocin diabetic rats. J Diab Comp 2: $185-188$

23. Tomlinson DR, Robinson JP, Compton AM (1989) Essential fatty acid treatment - effects on nerve conduction, polyol pathway and axonal transport in streptozotocin diabetic rats. Diabetologia 32: 655-659

24. Lands WEM (1992) Biochemistry and physiology of n-3 fatty acids. FASEB J 6: 2530-2536

25. Boulanger C, Schini V, Hendrickson H, Vanhoutte P (1990) Chronic exposure of cultured endothelial cells to eicosapentaenoic acid potentiates the release of endothelium-derived relaxing factor(s). BrJ Pharmacol 99: 176-180

26. Yin K, Chu Z, Beilin L (1991) Blood pressure and vascular reactivity changes in spontaneously hypertensive rats fed fish oil. $\mathrm{Br}$ J Pharmacol 102: 991-997 
27. McVeigh GE, Brennan GM, Johnston GD et al. (1993) Dietary fish oil augments nitric oxide production or release in patients with type 2 (non-insulin-dependent) diabetes mellitus. Diabetologia 36: $33-38$

28. Cameron NE, Leonard, MB, Ross IS, Whiting PH (1986) The effects of Sorbinil on peripheral nerve conduction velocity, polyol concentrations and morphology in the streptozotocin diabetic rat. Diabetologia 29: 168-174

29. Cameron NE, Cotter MA, Robertson S (1989) The effect of aldose reductase inhibition on the pattern of nerve conduction deficits in diabetic rats. Q J Exp Physiol 74: 917-926

30. Ziada AMAR, Hudlická O, Tyler KR, Wright AJA (1984) The effect of long term vasodilation on capillary growth and performance in rabbit heart and skeletal muscle. Cardiovasc Res 18: $724-732$

31. Seneviratne KN, Peiris OA (1969) The effects of hypoxia on the excitability of the isolated peripheral nerves of alloxan-diabetic rats. J Neurol Neurosurg Psychiat 32: 462-469

32. Horrobin DF, Manku MS (1990) Clinical biochemistry of essential fatty acids. In: Horrobin DF (ed) Omega-6 essential fatty acids: pathophysiology and roles in clinical medicine. Liss, New York, pp 21-54

33. Cotter MA, Cameron NE, Dines KC, Maxfield E, Robertson S, Cox D (1992) The effect of evening primrose oil on nerve conduction in diabetic rats depends on product(s) of cyclooxygenase-mediated gamma-linolenic acid metabolism. Diabetic Med 9 [Suppl 1]: A12 (Abstract)

34. Yasuda H, Sonobe M, Yamashita M et al. (1989) Effect of prostaglandin $\mathrm{E}_{1}$ analogue TFC 612 on diabetic neuropathy in streptozotocin-induced diabetic rats: comparison with aldose reductase inhibitor ONO2235. Diabetes 38: 832-838

35. Ito $H$, Kanazawa A, Ohno A et al. (1990) Effect of prostaglandin $\mathrm{E}_{1}, \mathrm{E}_{2}$ and $\mathrm{I}_{2}$ derivatives and methyl- $\mathrm{B}_{12}$ on peripheral neuropathy in diabetic rats: effects on sciatic nerve cyclic AMP, sorbitol and myo-inositol content. In: Ward JD, Goto Y (eds) Diabetic neuropathy. Wiley, Chichester, pp 517-524

36. Horrobin DF, Carmichael HA (1992) Essential fatty acids in relation to diabetes. In: Horrobin DF (ed) Treatment of diabetic neuropathy a new approach. Churchill Livingstone, Edinburgh, pp 21-40

37. Hwang DH, Boudreau M, Chanmugam P (1988) Dietary linolenic acid and longer-chain n-3 fatty acids: comparison of effects on arachidonic acid metabolism in rats. J Nutr 118: 427-437

38. Sinclair HM (1990) History of essential fatty acids. In: Horrobin DF (ed) Omega-6 essential fatty acids: pathophysiology and roles in clinical medicine. Liss, New York, pp 1-20

39. Oliver MF, Riemersma RA, Thomson M, Fulton M, Abraham RA, Wood DA (1990) Linoleic acid and coronary heart disease. In: Horrobin DF (ed) Omega-6 essential fatty acids: pathophysiology and roles in clinical medicine. Liss, New York, pp 121-126

40. Leeds AR, Gray I, Ahmed M (1990) Effects of n-6 essential fatty acids as evening primrose oil in mild hypertension. In: Horrobin DF (ed) Omega- 6 essential fatty acids: pathophysiology and roles in clinical medicine. Liss, New York, pp 157-172

41. Robertson S, Cameron NE, Cotter MA, Dines K (1992) Timecourse of reversal of nerve conduction deficits by aldose reductase inhibition, evening primrose oil, chronic electrical stimulation, and angiotensin converting enzyme inhibition in streptozotocin-diabetic rats. Diabetic Med 9 [Suppl 2]: P58 (Abstract)

42. Strupp M, Bostock H, Weigl P, Piwernetz K, Renner R, Grafe P (1990) Is resistance to ischaemia of motor axons in diabetic subjects due to membrane depolarization? J Neurol Sci 99: 271-280

43. Maruhashi J, Wright EB (1967) Effect of oxygen lack on single isolated mammalian (rat) nerve fiber. J Neurophysiol 30: 434452

44. Tarozzi G, Barzatini V, Maranesi M, Turchetto E (1989) Dietaryinduced changes in lipid and fatty acid composition can modify chronaxie values in the rat sciatic nerve. Ann Nutr Metab 33: $108-113$

45. Julu POO (1990) $\gamma$-linolenic acid: a novel remedy for diabetic neuropathy in experimental animals. In: Horrobin DF (ed) Omega- 6 essential fatty acids: pathophysiology and roles in clinical medicine. Liss, New York, pp 465-476

46. Horrobin DF, Durand LG, Manku MS (1977) Prostaglandin E modifies nerve conduction and interferes with local anaesthetic action. Prostaglandins 14: 103-108

47. Parry GJ, Kohzu H (1990) Acute changes in blood glucose affect resistance to ischemic nerve conduction failure. Neurology 40: $107-110$

48. Strupp M, Jund R, Schneider U, Grafe P (1991) Glucose availability and sensitivity to anoxia of isolated rat peroneal nerve. Am J Physiol 261: E389-E394

49. Calcutt NA, Ettlinger CB, Carrington AL, Diemel L, Tomlinson DR (1991) Resistance to hypoxic conduction block in sciatic nerves of rats with streptozotocin-induced diabetes mellitus. J Neurol Sci 103: 116-123

50. Cameron NE, Cotter MA (1992) Impaired contraction and relaxation in aorta from streptozotocin-diabetic rats: role of polyol pathway activity. Diabetologia 35: 1011-1019

51. Tesfamariam B, Brown ML, Cohen RA (1992) Aldose reductase and myo-inositol in endothelial cell dysfunction caused by elevated glucose. J Pharmacol Exp Ther 263: 153-157

52. Dvornik D (1987) Hyperglycemia in the pathogenesis of diabetic complications. In: Porte D (ed) Aldose reductase inhibition. An approach to the prevention of diabetic complications. Biomedical information corporation, New York, pp 69-151

53. Moncada S (1980) Prostacyclin and thromboxane $\mathrm{A}_{2}$ in the regulation of platelet-vascular interactions. In: Remuzzi $G$, Mecca $G$, de Gaetano G (eds) Homeostasis, prostaglandins and renal disease. Raven Press, New York, pp 175-188

54. Moncada S, Gryglewski RJ, Bunting S, Vane JR (1976) A lipid peroxide inhibits the enzyme in blood vessel microsomes that generates from prostaglandin endoperoxides the substance (prostaglandin X) which prevents platelet aggregation. Prostaglandins 12: 715-737

55. Cameron NE, Cotter MA, Maxfield EK (1993) Anti-oxidant treatment prevents the development of peripheral nerve dysfunction in streptozotocin-diabetic rats. Diabetologia 36: 299304

56. Picard S, Parthasarathy S, Fruebis J, Witztum JL (1992) Aminoguanidine (AMGN) inhibits LDL oxidative modification. Diabetes 41 [Suppl 1]: 17 A (Abstract)

57. Cameron NE, Cotter MA, Dines KC, Love A (1992) Effects of aminoguanidine on peripheral nerve function and polyol pathway metabolites in streptozotocin-diabetic rats. Diabetologia 35: 946-950

58. Kihara M, Schmelzer JD, Poduslo JF, Curran GL, Nickander KK, Low PA (1991) Aminoguanidine effects on nerve blood flow, vascular permeability, electrophysiology and oxygen free radicals. Proc Natl Acad Sci USA 88: 6107-6111

59. Hudlická O, Tyler KR (1986) Angiogenesis: the growth of the vascular system. Academic Press, New York

60. Keen H, Payan J, Allawi J et al. (1993) Treatment of diabetic neuropathy with $\gamma$-linolenic acid. Diabetes Care 16: 8-15

Received: 1 March 1993

and in revised form: 14 June 1993

Dr. N.E. Cameron

Department of Biomedical Sciences

University of Aberdeen

Marischal College

Aberdeen AB9 1 AS

Scotland, UK 